$\xi=-1$

\title{
Optimal reconfiguration of distribution network
}

\author{
V. Rajesh $\operatorname{Kumar}^{1} *$, V. Sai Kiran ${ }^{1}$ \\ ${ }^{1}$ UG Student, Dept. of EEE, Koneru Lakshmaiah Education Foundation, Guntur, AP, India 2UG Student, Dept. of EEE, Koneru Laksh- \\ mana Education Foundation, Guntur, AP, India \\ *Corresponding author E-mail: rajr7135@gmail.com
}

\begin{abstract}
This paper proposes a simple method for solving the distribution system reconfiguration to improve the voltage profile and reduce the losses. In this paper power flow studies are used in matrix form of distribution system with radial, weakly meshed and reconfigured forms. The execution of power flow will specify the bus voltages and branch currents. These parameters are used to analyse the system performance and especially branch currents information is used to convert system radial form to weakly meshed and reconfiguration forms by closing the tie-switches and opening the sectionalizing switches. The same information can be used in large networks to show the improvement in voltage profile and reduction in electrical losses.
\end{abstract}

Keywords: Distribution System; Improvement in Voltage Profile; Power Flow Studies; Power Losses; Reconfiguration

\section{Introduction}

Distribution system reconfiguration is very important to intensify the quality and reliability of the distribution network. Since the $\mathrm{R} / \mathrm{X}$ ratio of distribution network is more than that of the transmission network, the system is considered to be ill-conditioned. So, the power flow studies, normally used in power systems, like 'Newton-Raphson' and 'Fast Decoupled' methods, may not be suitable in distribution networks [1]. Due to the high resistance of distribution network, the cumulative real power losses increase in the distribution system. In order to reduce the losses, network reconfiguration is performed frequently on the distribution system [2].In an electrical distribution system, the structure of the network is, primarily, radial and, in some cases, weakly meshed. Radial distribution system is suitable for low voltage generation and when the station is placed at the medial point of load. Consumers at the farthest end of a distributor suffer from drastic fluctuations in voltage whenever the load changes. As customers depend on singly-fed systems, a fault upon the feeder causes interruption in supply to all the customers. So, radial system has less reliability. In order to improve the reliability and maintain better voltage profile, meshed distribution networks are used. Meshed networks are formed by closing the tie-switches, which are introduced in the radial network. Meshed network has multiple connections to provide supply to the other points. This helps in isolation of faults and to supply restoration so as to improve the system reliability.

Inarguably, meshed system is better than the radial system but to improve the latter is voltage profile, it can be reconfigured. Here, the interconnected network is break up at a number of points. So, it is converted into radial network where each point will open one simple loop.

To perform reconfiguration, the network is additionally equipped with sectionalizing switches and tie switches. While reconfiguring, sectionalizing switches are usually closed and are supposed to open to perform the operation. Tie switches, on the other hand, are usually open and are supposed to close in order to perform the operation [3].

These switching operations are provided to maintain the radial nature of the network and to energize loads. Generally, tie switches are closed in order to deliver load to and from feeders, and to form meshed network while a proper sectionalizing switch is opened to bring back the structure into radial form. Earlier, power flow solutions are obtained for a radial network by using backward and forward sweep method. Nodal currents are calculated in case of backward sweep and voltages in case of forward sweep. The nodal powers are non-linear functions of nodal voltage. So, the solution is iterative. The solution takes up to five iterations if the system is not ill-conditioned. This method is not applicable to the weakly meshed system which is the main subject in this paper. So, matrix method can effectively use for distribution system having dispersed generation.

Mesut Baran et.al., [4] proposed network reconfiguration in distribution system. Here, reconfiguration is done by varying the status of sectionalizing switches. It helps in reducing the losses and balancing the load.

M.Tarafdar Hagh, T.Ahamadzadeh et.al., [5] proposed a matrix method acquired from KVL and KCL to get load flow solutions on distribution network with and without considering distributed generations.

T. Thakur and Jaswanti Dhiman et.al., [6] have presented a load flow solution method for a radial distribution system. The paper presents a new approach, in which the switches to be opened is decided based on the voltage calculated at the buses, real power and reactive power flowing through lines, losses in real power and deviation in voltage, using distribution load flow (DLF) program. The methodology proposed in this paper has the objective of studying the effect of distribution system reconfiguration in voltage profile and losses. It is tested on IEEE 33-bus system having five tie switches. In second section, load flow analysis is done on radial distribution network with matrix method. In third section load flow analysis is done on weakly meshed distribution network with matrix method. In section four, reconfiguration methodology 
is presented. In section five and six contains results of simulation and conclusions respectively.

\subsection{Direct matrix approach for distribution system}

This method consists of two matrices, which were developed by the advantage of topological characteristics of distribution system and solves the load flow without deviation. The two matrices are namely 'BIBC' (Bus injection to branch current) and 'BCBV' (Branch current to bus voltage) matrices. These matrices can be obtained by calculating the Equivalent current injections or Admittance matrix. The IEEE 33-bus system is taken as a test system in this paper. In order to compute load flow on the distribution system the following steps are required.

\subsection{Calculation of equivalent current injections}

The equivalent current injections are calculated by equation (1).

$$
\mathrm{I}_{\mathrm{i}}^{\mathrm{k}}=\left(\frac{\mathrm{S}_{\mathrm{i}}}{\mathrm{V}_{\mathrm{i}}^{\mathrm{k}}}\right)^{*}=\left[\left(\mathrm{P}_{\mathrm{i}}+\mathrm{j} \mathrm{Q}_{\mathrm{i}}\right) / \mathrm{V}_{\mathrm{i}}^{\mathrm{k}}\right]^{*}
$$

Where $\mathrm{i}$ is the bus number and $\mathrm{k}$ is the iteration number. $\mathrm{P}_{\mathrm{i}}$ and $\mathrm{Q}_{\mathrm{i}}$ are active and reactive power of the bus respectively.

\section{Load flow analysis for radial distribution system}

The IEEE 33-bus system is taken in this paper to analyse the performance of proposed methodology on a Radial network.

\subsection{Formation of BIBC matrix for radial network}

It is obtained by applying the KCL in a distribution network. The relation between bus current injection and branch currents can be represented as BIBC matrix. Branch current is related with bus current as shown in equation (2).

$[\mathrm{B}]=[\mathrm{BIBC}][\mathrm{I}]$

Where, $[\mathrm{B}]$ is the branch current, $[\mathrm{I}]$ is the bus current and $[\mathrm{BIBC}]$ is the bus injection to branch current, it is a upper triangular matrix represented with ones.

In conventional backward and forward sweep algorithm which is used in load flow studies of distribution system, the branch currents are computed in backward sweep operation which is represented as equation (2) in the present method.

\subsection{Formation of BCBV matrix for radial network}

The relation between Branch currents and bus voltages can be represented as BCBV matrix. It is obtained by adding the voltage drops behind a bus $i$ to obtain the voltage drop at the bus $i$.

$$
\begin{aligned}
& {\left[\Delta \mathrm{V}_{\mathrm{i}}\right]=\left[\mathrm{Z}_{\mathrm{ij}}\right][\mathrm{B}]} \\
& {\left[\Delta \mathrm{V}_{\mathrm{i}}\right]=\left(\mathrm{V}_{1}-\mathrm{V}_{\mathrm{i}}\right)}
\end{aligned}
$$

Where $\left[\Delta \mathrm{V}_{\mathrm{i}}\right]$ is a vector in which the voltage drops of the buses are measured from the root node.

The relation between the branch currents to the branch voltage is expressed as equation (4).

$[\Delta \mathrm{V}]=[\mathrm{BCBV}][\mathrm{B}]$

In conventional backward and forward sweep algorithm which is used in load flow studies of distribution system, the bus voltages are computed in forward sweep operation which is represented as $\mathrm{BCBV}$ matrix in the present method. It is a lower triangular matrix represented by branch impedances.

\subsection{Computation of distribution load flow}

Branch currents are calculated from eqn. (2) and Bus voltages are calculated from eqn. (4). By combining the both equations, the voltage deviations from the root node can be expressed as eqn. (5).

$[\Delta \mathrm{V}]=[\mathrm{BCBV}][\mathrm{BIBC}][\mathrm{I}]$

$[\Delta \mathrm{V}]=[\mathrm{DLF}][\mathrm{I}]$

This matrix represents the relation between the current injection and bus voltages. The equations (3), (4) and (5) make the algorithm iterative. The latest bus voltage is obtained for the voltage of previous iteration as shown in eqn. (6)

$\mathrm{V}^{\mathrm{k}+1}=\mathrm{V}_{1}-[\mathrm{DLF}]\left[\mathrm{I}^{\mathrm{k}}\right]$

The algorithm takes up to five iterations, if the system is not illconditioned. The solution is terminated when the difference between the bus voltages of previous and current iteration is within the tolerance value $\varepsilon=10^{-4}$.

\section{Load flow analysis for weakly meshed dis- tribution system}

Normally the distribution system is operated in radial form for the simplicity of protection. But in emergency conditions the customers at the end of the feeder get affected. So, the system is provided with tie switches for changing the configuration during emergencies to keep the system reliable. In this paper the IEEE 33-bus system has 5 tie switches. By closing a single tie switch, a loop is formed. So, it gives a better voltage profile.

\subsection{Formation of BIBC matrix for weakly meshed net- work}

A closure of a tie switch in the network results in a branch flow which in turn changes the branch current flow, the [B] vector in eqn. (2) takes a new updated value. The new branch formed results in flow of current from high voltage bus to low voltage bus and a meshed current in opposite direction in some of the branches. This mesh current is superimposed on the already existing branch flows.

The normal form of altered BIBC matrix is

$\left[\begin{array}{c}\mathrm{B} \\ \mathrm{B}_{\text {new }}\end{array}\right]=[\mathrm{BIBC}]\left[\begin{array}{c}\mathrm{I} \\ \mathrm{B}_{\text {new }}\end{array}\right]$

\subsection{Formation of BCBV matrix for weakly meshed network}

It can be obtained by applying the KLV in the mesh loop formed. The modified BCBV is obtained by adding the meshed currents which is governed by the KVL to eqn. (4).

The normal form of altered BCBV matrix is

$\left[\begin{array}{c}\Delta \mathrm{V} \\ 0\end{array}\right]=[\mathrm{BCBV}]\left[\begin{array}{c}\mathrm{B} \\ \mathrm{B}_{\mathrm{new}}\end{array}\right]$

By substituting eqn. (7) and (8) the relation between the current injection and bus voltages is obtained as eqn. (9).

$\left[\begin{array}{c}\Delta \mathrm{V} \\ 0\end{array}\right]=\left[\mathrm{DLF}_{\text {new }}\right]\left[\begin{array}{c}\mathrm{I} \\ \mathrm{B}_{\text {new }}\end{array}\right]$

The DLF matrix in eqn. (9) has dimension of $33 * 33$ for the system considered and it is reduced to $32 * 32$ by Kron's reduction.

Therefore the altered algorithm for weakly meshed network is

$[\Delta \mathrm{V}]=[\mathrm{DLF}][\mathrm{I}]$ 
The iterative method for solution of eqn. (10) is same as for radial network.

\section{Reconfiguration of distribution system}

Normally the meshed distribution system gives better voltage profile than radial system but to improve the voltage profile, the meshed system is again converted to radial form by opening sectionalizing switches. Reconfiguration is a task, which are performed frequently on distribution system to reduce losses and improve voltage profile. Basically, reconfiguration is a process of changing the topological structure of distribution network. These changes are made by changing the status of sectionalizing and tie switches. In the present methodology after sequentially closing the tie switches the system form is changed into mesh and with opening of sectionalizing switches carrying minimum current the system form is changed to radial. The present system contains five tie and sectionalizing switches respectively.

\subsection{Algorithm}

1) Read the input data

2) Calculate the bus injection currents.

$\mathrm{I}_{\mathrm{i}}^{(\mathrm{k})}=\left(\mathrm{S}_{\mathrm{i}} / \mathrm{V}_{\mathrm{i}}^{\mathrm{K}}\right)^{*}=\left(\mathrm{P}_{\mathrm{i}}+\mathrm{j} \mathrm{Q}_{\mathrm{i}} / \mathrm{V}_{\mathrm{i}}^{\mathrm{k}}\right)^{*}$

3) Form BIBC matrix to compute the branch currents.

$[\mathrm{B}]=[\mathrm{BIBC}][\mathrm{I}]$

4) Form BCBV matrix to calculate bus voltages.

$[\Delta \mathrm{V}]=[\mathrm{BCBV}][\mathrm{B}]$

5) Calculate the DLF matrix by using BCBI and BCBV matrix as eqn. (5).

6) Calculate $[\Delta \mathrm{V}]$ by using obtained injection currents, then update the voltage.

$[\Delta \mathrm{V}]=[\mathrm{BCBV}][\mathrm{BIBC}][\mathrm{I}]=[\mathrm{DLF}][\mathrm{I}]$

7) Check for convergence.

$\left|\mathrm{V}^{\mathrm{k}+1}-\mathrm{V}^{\mathrm{k}}\right| \geq \epsilon$

\section{Simulation results}

The IEEE 33-bus system was taken to test the algorithm. The load flow studies are made on the following distribution systems.

a) Radial system

b) Weakly meshed system

c) Reconfigured system

The voltage profile and the real power losses are observe in each system.

\subsection{Load flow analysis on IEEE 33-bus system}

\subsubsection{Radial system}

The IEEE 33-bus system consists of 33 buses with 32 branches and five tie-switches. In radial form all the tie switches are in unclosed position. The minimum voltage obtained after running the load flow is $0.915 \mathrm{p}$.u, which occurred at bus number 18 and the maximum voltage is 0.9969 p.u. occurred at bus 2 , which is very far from the substation. The overall power losses of the system is 0.0049 p.u.

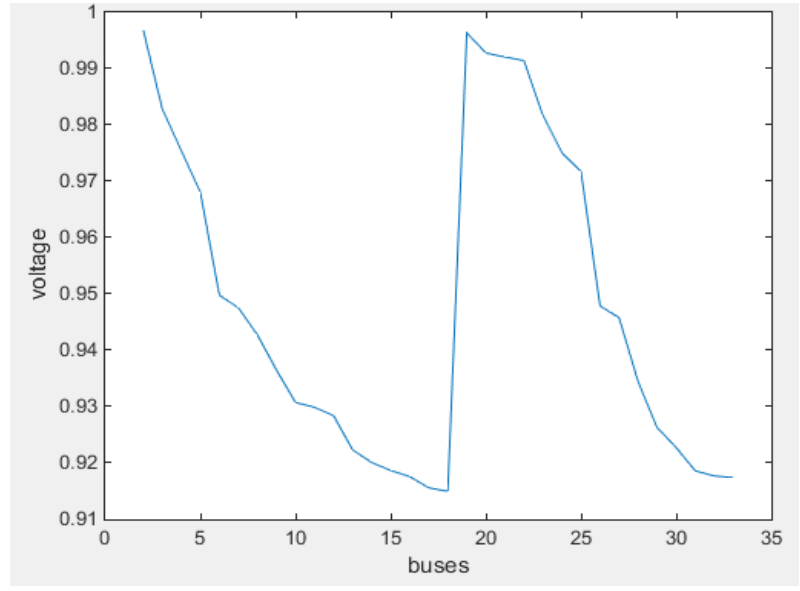

Fig. 1:- Voltage Profile of Radial System.

Table 1:- Minimum Voltage and Losses of Radial System

\begin{tabular}{lll}
\hline Minimum Voltage & Minimum Voltage bus & Losses \\
\hline 0.915 & 18 & $0.0049 \mathrm{p} . \mathrm{u}$
\end{tabular}

In fig 1: There is a sudden rise in voltage at bus 19 because it is very nearer to substation.

\subsubsection{Weakly meshed system}

To improve the voltage profile the tie switches are closed one by one to bring the system into meshed form. The five tie switches to be closed are $\mathrm{B}_{33}, \mathrm{~B}_{34}, \mathrm{~B}_{35}, \mathrm{~B}_{36}$ and $\mathrm{B}_{37}$. The voltage profile and losses are computed each time. Total five cases are observed where each case represents closer of one tie switch.

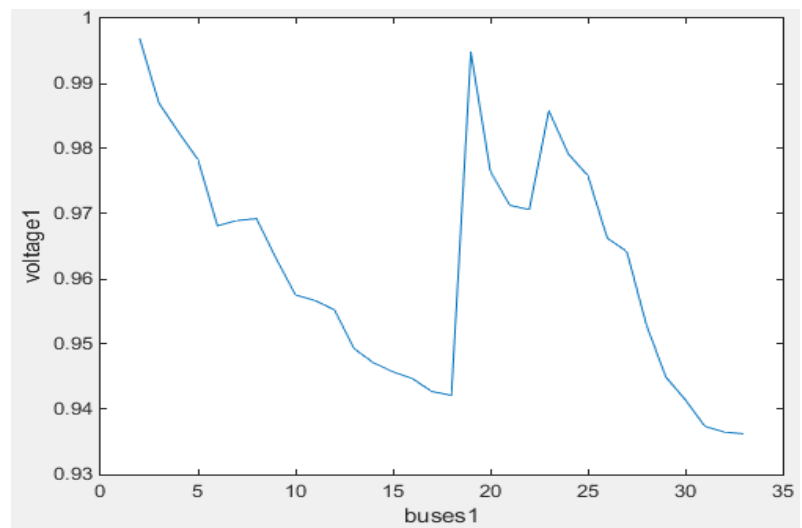

Fig. 2:- Voltage Profile of Meshed System when $B_{33}$ Tie Switch is Closed.

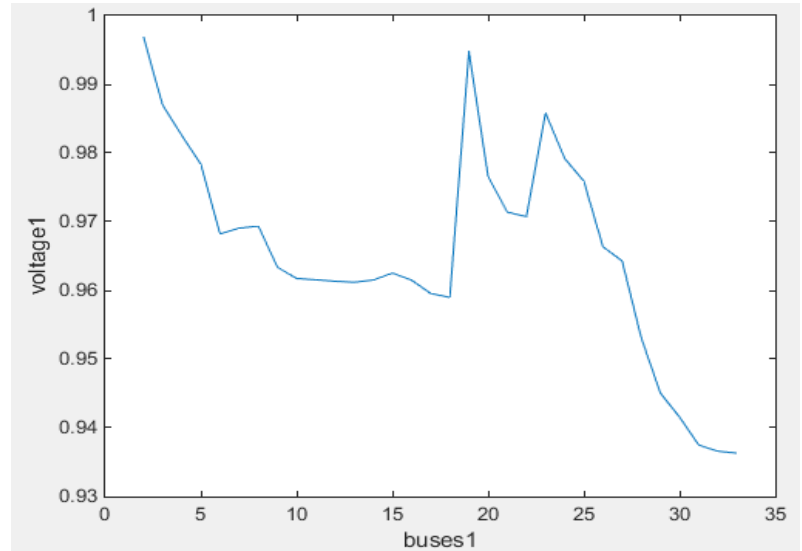

Fig. 3: Voltage Profile of Meshed System when $B_{33}$ and $B_{34}$ Tie Switches Are Closed. 


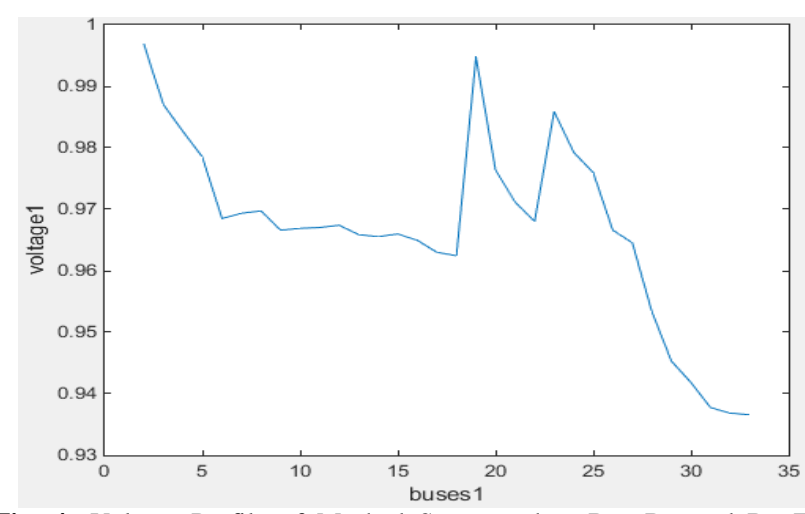

Fig. 4: Voltage Profile of Meshed System when $B_{33}, B_{34}$ and $B_{35}$ Tie Switches are Closed.

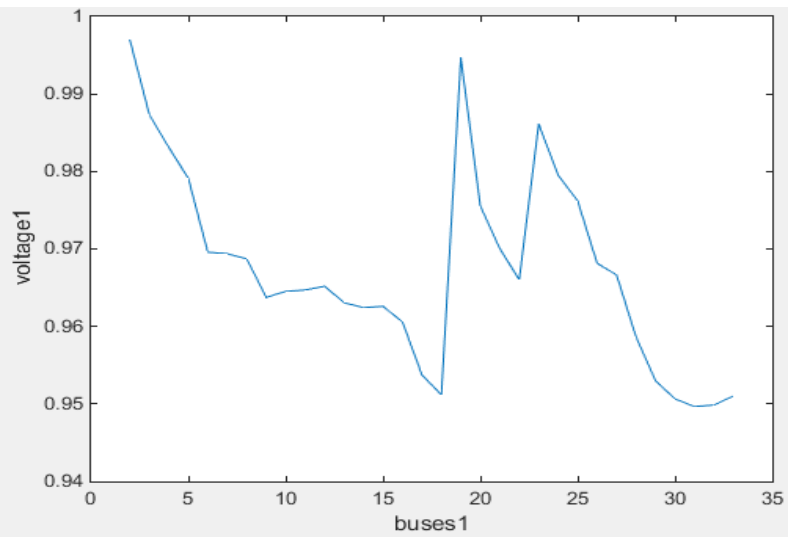

Fig. 5: Voltage Profile of Meshed System when $B_{33}, B_{34}, B_{35}$ and $B_{36}$ Tie Switches Are Closed.

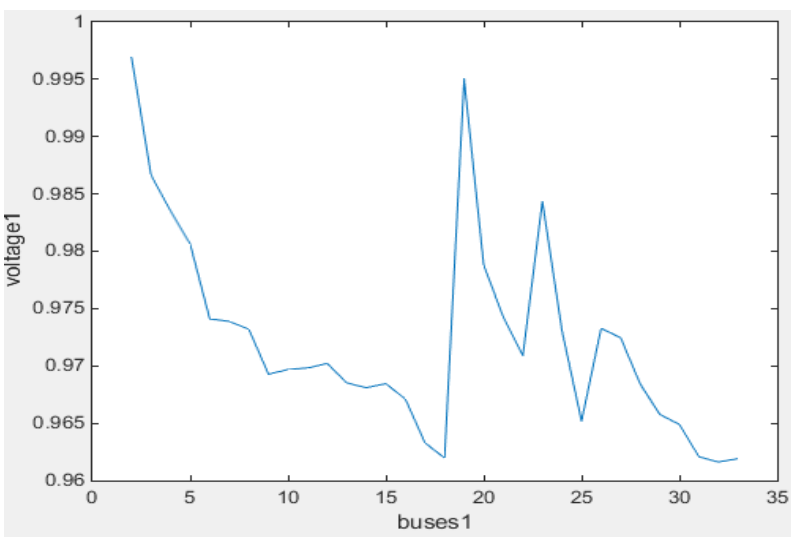

Fig. 6: Voltage Profile of Meshed System when All $\mathrm{B}_{33}, \mathrm{~B}_{34}, \mathrm{~B}_{35}, \mathrm{~B}_{36}$ and $\mathrm{B}_{37}$ Tie Switches Are Closed.

Table 2: Voltage Profile and Losses of the Meshed System with Sequential Closing of Tie Switches

\begin{tabular}{llll}
\hline $\begin{array}{l}\text { Tie switches } \\
\text { Closed }\end{array}$ & $\begin{array}{l}\text { Minimum Volt- } \\
\text { age }\end{array}$ & $\begin{array}{l}\text { Minimum Voltage } \\
\text { bus }\end{array}$ & Losses \\
\hline $\mathrm{B}_{33}$ & 0.9362 & 33 & $0.0025 \mathrm{p} . \mathrm{u}$ \\
$\mathrm{B}_{33}, \mathrm{~B}_{34}$ & 0.9363 & 33 & $0.0024 \mathrm{p} . \mathrm{u}$ \\
$\mathrm{B}_{33}, \mathrm{~B}_{34}, \mathrm{~B}_{35}$ & 0.9366 & 33 & $0.0023 \mathrm{p} . \mathrm{u}$ \\
$\mathrm{B}_{33}, \mathrm{~B}_{34}, \mathrm{~B}_{35}, \mathrm{~B}_{36}$ & 0.9497 & 31 & $0.0022 \mathrm{p} . \mathrm{u}$ \\
$\mathrm{B}_{33}, \mathrm{~B}_{34}, \mathrm{~B}_{35}, \mathrm{~B}_{36}$, & 0.9616 & 32 & $0.0022 \mathrm{p} . \mathrm{u}$ \\
$\mathrm{B}_{37}$ & & & \\
\hline
\end{tabular}

\subsubsection{Comparison of radial and meshed system}

By closing all the tie switches, the system is in weakly meshed form. In meshed system the minimum voltage has occurred at bus 32 , its voltage value is 0.9616 p.u. The losses are 0.0022 p.u.

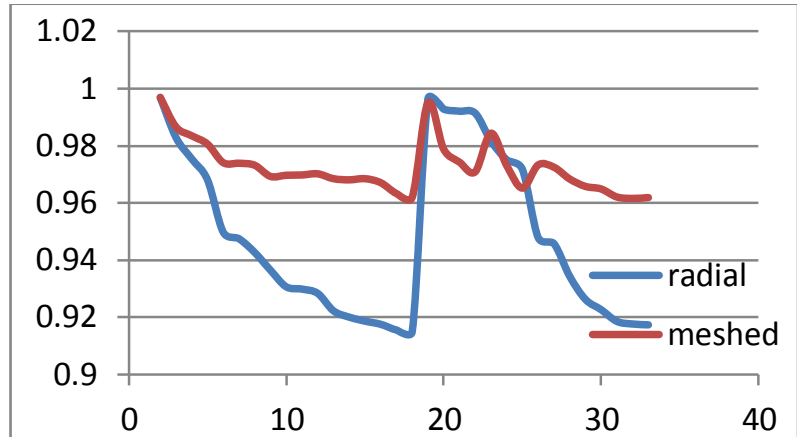

Fig. 7: Voltage Profile of Both Radial and Meshed System.

The voltage profile is improved when all the tie switches are closed and the system losses are reduced when compared to system in radial form.

Table 3: Voltage Profile and Power Loses in both Radial and Meshed System

\begin{tabular}{llll} 
System & $\begin{array}{l}\text { Minimum } \\
\text { Voltage }\end{array}$ & $\begin{array}{l}\text { Minimum } \\
\text { Voltage bus }\end{array}$ & Losses in \\
\hline $\begin{array}{l}\text { Radial (all tie switches opened) } \\
\begin{array}{l}\text { Meshed (all tie switches } \\
\text { closed) }\end{array}\end{array}$ & 0.915 & 18 & $0.0049 \mathrm{p} . \mathrm{u}$ \\
\hline
\end{tabular}

\subsection{Reconfiguration of distribution system}

The radial system is converted into mesh system by using tie switches to improve the voltage profile and reduce losses. In reconfiguration the meshed system is again converted in radial form by opening the sectionalized switches sequentially at a time. The switch which carries the minimum current has to be opened. To select the next switch, power flow has to be run to examine the minimum current flow in the branches.

This process has to be done sequentially till the system gets into full radial form with a different topology. The sectionalized switches opened after closure of all tie switches to get the better voltage profile are $\mathrm{B}_{7}, \mathrm{~B}_{9}, \mathrm{~B}_{10}, \mathrm{~B}_{14}$ and $\mathrm{B}_{26}$. The minimum voltage obtained after doing load flow is 0.9803 p.u at bus 25 and the losses obtained is 0.0015 p.u. 5

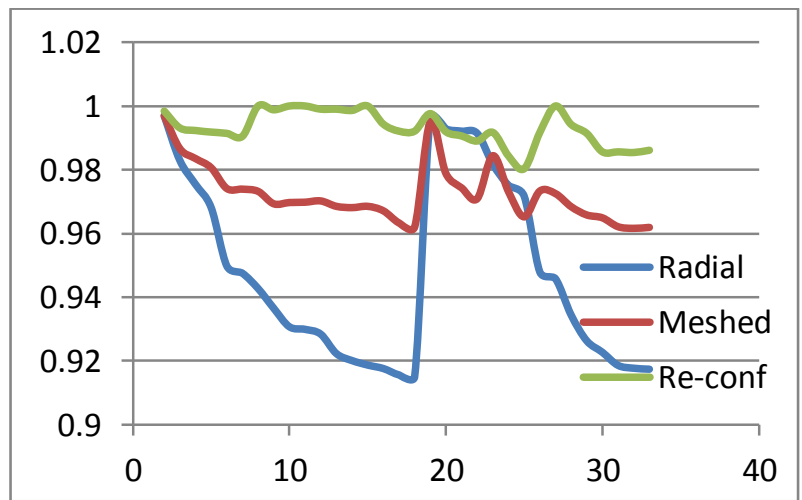

Fig. 8: Comparison between Voltage Profiles of Radial, Weakly Meshed and Reconfiguration Systems.

From the above figure it is clearly known that reconfiguration system will give the better voltage profile than the other two systems.

5.2.1. Comparison between radial, meshed and reconfiguration system

The voltage profile is better in meshed system compared to radial system and in reconfigured system the voltage profile is better than meshed system. The losses are also reduced in reconfiguration system compared to the other two systems.

Table 4: Minimum Voltage and Losses of Three Systems in Final Case 


\begin{tabular}{llll}
\hline System & $\begin{array}{l}\text { Minimum Volt- } \\
\text { age }\end{array}$ & $\begin{array}{l}\text { Minimum Voltage } \\
\text { bus }\end{array}$ & Losses \\
\hline Radial & 0.915 & 18 & 0.0049 p.u \\
Meshed & 0.9616 & 32 & $0.0022 \mathrm{p} . \mathrm{u}$ \\
Reconfigured & 0.9803 & 25 & $0.0015 \mathrm{p} . \mathrm{u}$ \\
\hline
\end{tabular}

\section{Conclusion}

The classical backward-forward power flow method cannot be used with meshed networks and hence the paper used the matrix method to compute the nodal voltage profile and losses by closing the system tie switches which brings the system into meshed form. Also, reconfigured network is studied after sequentially closing the tie switches and forcing the system into radial form with opening of sectionalizing switches carrying minimum current. The proposed methodology is tested on IEEE 33-bus system. The reconfigured network has good voltage profile and reduced losses.

\section{References}

[1] T. Ochi, D. Yamashita, K. Koyanagi, and R. Yokoyama, "The development and the application of fast decoupled load flow method for distribution system with high $\mathrm{R} / \mathrm{X}$ ratio lines," in innovation Smart Grid Technologies (TSGT), 2013 IEEE PES, 2013, pp 1-6.

[2] S. Elsaiah and J. Mitra, "A Method for Minimum Loss Reconfiguration of Radial Distribution System," 978-1-4673-80409/15/\$31.00 @2015 IEEE.

[3] C.-T. Su and C. -S. Lee, "Network reconfiguration of distribution systems using improved mixed-integer hybrid differential evolution," IEEE Transactions on Power Delivery, vol. 18, no. 3, pp. 1022-1027, 2003. https://doi.org/10.1109/TPWRD.2003.813641.

[4] M.E. Baran and F. F. Wu, "Network reconfiguration in distribution systems for loss reduction and load balancing," IEEE Transactions On Power Delivery, vol. 4 , no. 2, pp. 1401-1407, 1989 https://doi.org/10.1109/61.25627.

[5] M.Tarafdar Hagh and T.Ahamadzadeh, "Load Flow Analysis of Radial and Weekly Meshed Distribution System including DGs", Power engineering conference, AUPEC 2014.

[6] T. Thakur, and Jaswanthi Dhiman "A New Approach to Load Flow Solutions for Radial Distribution system", 1-4244-02883/06/\$20.00 (@2006 IEEE. 